\title{
Study on the Features and Creative Concept of Online Music Spreading Rui Pan ${ }^{1, a}$, Yan Jiang ${ }^{2, b}$ \\ ${ }^{1}$ Jiangxi Teachers College, Yingtan, Jiangxi, 335001 \\ a email, ${ }^{b}$ email
}

Keywords: Online Music Spread; Characteristics; Creation Concept

\begin{abstract}
Online music spread requires the use of network technology and computer technology, the transmission through the network platform, sending, and was listening to the recipient, to enjoy. Music transmission network belongs to a new form of communication of music, which changed many of the shackles and "impossible" to spread music spread, making music transfer even more efficient, convenient, and time and space are not affected. This focuses on the characteristics and creative ideas online music spread, in order to provide valid credentials for the benign development of online music.
\end{abstract}

\section{Introduction}

In the 21st century, people are faced with the change and development of large data. In the context of the era of big data, the network is affecting people's work, study and life. For online music spread, it is in this environment arising from [1]. As a new mode of transmission networks, online music spread improved many shortcomings of traditional music spread, so that the music becomes faster propagation speed, timeliness becomes stronger, in addition to not be affected by time and space, greatly It reflects the simple and fast characteristics. From the perspective of the development of online music spread article on the "online music propagation characteristics and creative ideas" to analyze and explore the value of the effect.

\section{Several Features of Network Music Communication}

Traditional Music in the form of a single, timeliness is not strong, you need through the creation, investigation, communication media, printing, recording and delivery of a number of links, etc., and many intermediate verification link, thus greatly reducing the propagation speed of the music. As for online music spread, it only needs the network platform, simply use the Internet and computer technology, will be able to achieve the distribution of music, making music in real time, effectively received by the listener, so as to realize the appreciation of music. To sum up, the spread of online music has the following characteristics:

For online music, in the dissemination process will be the integration of network elements, thus making it rich in the form of propagation characteristics is obvious. It can be implemented on many sites, or transfer music platform, such as QQ music, cool dog music, shrimp music, 5sing music. Of course, the music network transmission process, also need to be reviewed, mainly in order to maintain the initial permissions music filtering illegal or vulgar influence creative thinking, thus ensuring the health and other online music market, green and safe. In addition, the network also includes music online game music, computer music and MTV website background music. In short, the online music features of the rich forms of communication out on this remarkable feature is not available in Traditional Music, which is the spread of online music to conform to the trend of the key to development.

In fact, before the spread of online music has been initially referred to is not limited by time and space, that is, it reflects the significant features of online music spread wide range of purposes in a way. We might spread departure from traditional music, which need to go through multiple links and layers of review, the final distribution of music can be achieved, and that the spread of a single, can not be achieved "repeatedly" feature, it is difficult to meet the listener or viewer requirements [2]. As for online music spread, the music creators simply through the network platform, will be 
able to transmit real-time piece of music, and the music listener and the viewer can also repeatedly play, listen to music, thus largely to meet the needs of the users. In short, the online music spread wide range of prominent characteristics, so that the spread of online music and more prospects.

Traditional Music has been given a serious feature that sense of freedom is severely constrained, and for music transmission network, its respect for traditional music, is free, is not bound by many of the old rules. At the same time, online music in the communication process, in which the interaction characteristics are very prominent, that music creators and music listening or can be implemented between the viewer "barrier-free" interaction, discuss the advantages of musical works, defects, and music creators in the case of advice or the views of the listener or the viewer, will be able to improve their own lack of foundation for the future to create more public love good works. In short, the online music spread with notable features free, interactive, which is able to get online music loved by the public key.

\section{The Concept of Network Music Exploration}

In the analysis of the process, we learned some of the features of online music spread. Meanwhile, for online music, its creative concept and there is a big difference compared to traditional music. To sum up, the concept of network music performance are as follows:

Network platform for the music network provides diverse material, including popular music, classical music, folk music and vocal music, etc., can be used by creators, authors only need to collect network material, selection, combined with their own creation Features and inspiration, will be able to create a unique online music. At the same time, the presence of diverse musical style is characterized by the network platform, creators can also be their own style and other styles are fused to form a new network music style, which is also no lack of a diversified Writing mode [3]. In addition, the online music creators can also stream music from their own creation to different music sites, such as the cool dog music, QQ music, 5sing shrimp music and music; but also can be used as background music for websites, email, and music RBT music. All these characteristics are reflected in the concept of diversity online music creation.

Already mentioned above, the traditional music in the dissemination process will be multi-link, multi-level constraints so that the music relative loss of freedom. As for online music, its spread and to avoid the many aspects of hierarchy, so that the online music freed from the shackles of traditional music in a sense, so that the free characteristic is particularly evident. In this environment, network music creators in the process of making music also reflects the characteristics of freedom, thereby enabling the creation of music out of more personalized, specialized. For example: Some time ago a very fire, "my skateboard shoes," the author John Joseph Lang - Pangmai with their own experiences, creating a personalized music so rich, has been the public's favorite [4]. And Joseph John Lang • Pangmai personalized rap style and lack of standard Mandarin is also this piece of music was widely circulated to lay a foundation. All in all, the creative concept of personalized online music highlight one of the important factors in this is to develop a network of music.

Since the online music low threshold, high degree of liberalization, so many creators. At the same time, online music mostly from the private sector, so the idea of creation of life patterns is very prominent. That is, the online music in the creative process is often combined with the launching of daily life, thus making music more ground gas network more with the public's daily life standards, so that the listener resonate, thereby enabling online music audience volume increases. For example: A few years ago widely circulated "Two Butterflies" and its creator is inspired Pang Long "Butterfly Lovers" story found in [5]. In addition, the network also has a popular music creation idea, through real-time communication and interaction network, to create a public favorite, acceptable music, so will be able to further increase the amount of network audiences piece of music, so that creators wherein obtaining certain economic benefits and "fans" amount. In short, there is a creative concept of online music and traditional music is very different concepts, its creative concept of diversified features, which makes online music have good prospects for development. 


\section{Conclusion}

Through analysis and inquiry of this article, on the one hand learned online music spread several notable features, namely the spread of rich form, spread a broad range, high degree of freedom, can achieve real-time interaction. On the other hand, learned that online music has diverse creative idea that diversity, individuality, life and popularity like. All in all, online music propagation characteristics and creative ideas are reflected in the new and innovative, and dissemination of traditional music and ideas compared to a higher degree of freedom, it will not be bound or restricted by many factors, which makes the prospects for the development of online music and more . Furthermore, I believe that, in order to promote the healthy development of online music, in addition to understand the characteristics and creative ideas, there is need to integrate the online music market, strengthen the verification link to online music, online music to ensure a green, healthy, "positive energy" so that creators can create to the public hope that the power of online music works, the network music listener or the viewer can feel from the wonderful charm of music and life, and ultimately to lay a solid foundation for the healthy development of online music.

\section{References}

[1] Huang Shumin, Li Dandan. Affect network music for music creation and dissemination of analysis [J]. Music Space, 2013, 06: 92-93.

[2] Ruan Junyu. Creation and dissemination of artistic features of online music analysis [J]. Changchun University, 2014, 24: 424-426.

[3] Shao Ying. Study network popular music and propagation characteristics [J]. Music Space (Theory Edition), 2012, 02: 61-62.

[4] Zou Hao. Study popular music network communication process and characteristics [J]. Music Space, 2015, 22: 90.

[5] Wang Yue. Music and Popular Music Network Communication Concept Analysis [J]. Arts Education, 2016, 04: 79-81. 